\title{
Patients' knowledge of their condition and treatment: how it might be improved
}

\author{
HELEN DUNKELMAN
}

British Medical fournal, 1979, 2, 311-314

\section{Summary and conclusions}

A study was carried out in which patients were asked questions to assess their knowledge of their condition and treatment, the questions relating particularly to care before siting an intravenous infusion and preoperative care. A high proportion of patients knew little about the procedure they were about to undergo.

It is recommended that patients should be told more about matters relating to their condition and treatment. Written information could be given to supplement that given verbally by staff. A check list might be drawn up to ensure that patients receive all relevant information.

\section{Introduction}

During my training I nursed patients from various backgrounds and with different levels of understanding of medical terminology and practice. I was thus interested in finding out how much patients understood of their condition and treatment and how much they remembered of information given to them. Patients may be apprehensive when they reach hospital and might have been misinformed by well-meaning friends or articles in the press. Moreover, the information given by the medical team may be inconsistent, perhaps due to lack of consultation or to disagreement on exactly how much information should be given. Indeed, there may be no set procedure for determining which member of staff is to give such information. I am often

9A Links Way, Northwood, Middlesex HA6 2XA

HELEN DUNKELMAN, SRN, lately staff nurse, University College Hospital, London WC1 confronted by patients and relatives asking for information, and find it a problem to decide how much they should be told. In this study I attempted to clarify the problem and suggest some possible solutions.

\section{Methods}

Two basic approaches, formal and informal, were possible for this study. The formal approach uses a predetermined, written set of questions (some open-ended), which are asked by the researcher in a specific order. Answers are recorded as they are given, and confidentiality is ensured. For the informal approach a basic set of questions is drawn up, and the questioner tries to keep to them as closely as possible without making it explicit that they are being asked. The formal method has the advantage of precision, as the questions provide data that are directly comparable. Each patient is asked the same questions with no variations, and since the answers are recorded as they are given they cannot be distorted. In addition, the questioner can move systematically round the ward and so question all the patients without needing to wait until he is treating the patient. This approach, however, might be frightening to the patient, who might feel inadequate and that he was being tested in some way.

Although the formal method would have been preferable for this study because of its greater precision and objectivity, the informal method was selected as it was thought to be preferable from the patient's point of view. This restricted the number of patients I could question to those with whom I could chat while I carried out my nursing duties. I excluded certain patients from the survey owing to their mental or physical incapacity. In the study I covered the female surgical, male surgical, and male medical wards and the accident and emergency ward and department.

\section{Questions and results}

I examined two aspects of patient care-namely, care before siting an intravenous infusion and preoperative care. The following questions were used to obtain information. 
CARE BEFORE SITING INTRAVENOUS INFUSION

Twenty-two patients in whom an intravenous infusion was to be used were asked the following questions.

Are you expecting a drip?-Seventeen patients were not, while five patients were expecting a drip to be used.

Do you understand the purpose of a drip?-Fourteen patients did not realise what the intravenous infusion was for.

Do you know what the fluid is? - Fifteen patients did not know what fluid was contained in the bottle.

Do you know where the fluid is going?-Twelve patients did not know where the fluid was going, and of the 10 who said that they did know, only eight gave correct answers.

How long do you expect the drip to be used ?-Four patients knew how long the drip would operate, one thought he knew but in fact answered incorrectly, and 17 didn't know.

Are you expecting to be able to eat and drink after the operation?Seven patients thought that they would be able to eat and drink after the operation, four correctly and three incorrectly. Six patients did not expect to be able to, three correctly. Nine patients didn't know. When the six patients who did not expect to be able to eat and drink were asked when they thought they might resume doing so, three gave correct answers in each case.

\section{PREOPERATIVE CARE}

Before the operation it is routine to shave the operation area. Did you expect this? Do you know why this is done?-Nine out of the 16 patients asked expected to have the operation area shaved, but only five knew why this procedure was carried out.

Before bowel surgery it is usual to give suppositories. Do you know what these are and why they are given. Do you understand why they are necessary?-Out of 12 patients asked, six knew what a suppository was, six knew how they were given, and five understood why they were necessary.

You will be given a preliminary injection before your anaesthetic. Were you expecting this? Do you know the reason for this?-Nine out of 14 patients were not expecting any premedication, and nine did not know why it was given.

Where and in what form do you think the anaesthetic is administered? -Out of 16 patients asked these questions, four knew the anaesthetic would be administered, one answered incorrectly, and the remainder didn't know. Five patients knew how the anaesthetic was given, two thought they did but answered incorrectly, and nine didn't know.

Do you understand what the operation consists of? Do you know why you are having it?-Eight out of 16 patients said that they knew what the operation consisted of, but only seven described the procedure accurately. In only seven of the nine patients who thought that they knew why they were having the operation were the reasons given correct; the remaining seven patients did not know the reason for their operation.

Do you know where you will come round from the anaesthetic?Eleven out of 16 patients did not know where they would come round from the anaesthetic; five thought that they knew, but only two answered correctly.

\section{Discussion}

From this study it appears that insufficient information is given to patients about their condition and treatment and that their misconceptions are not being dispelled. While I studied only two sample areas of information-giving, a similar lack of knowledge probably prevails for other aspects of treatment-for example, $x$-ray procedures, radiotherapy, suturing, blood tests, and electrocardiography. In certain cases detailed information is necessary because of particular problems, such as in patients who have undergone colostomy, ileostomy, mastectomy, or hysterectomy; diabetics; and those who have suffered a myocardial infarction. It is these patients who have long-term emotional and physical difficulties. Specialised societies already exist for them, many run by past patients and relatives, and besides publishing information they will often arrange visits, which are beneficial to the patients.

Thus some procedure is necessary that attempts to promote healing and recovery by-dispelling fears and clarifying mis- conceptions. The link between the psychological and physiological is well documented, and recovery from a physical illness may be improved by considering the patients' mental as well as physical wellbeing.

\section{Recommendations}

Perhaps the most frightening result of this study was that half of the patients asked were apparently ignorant of the nature of their operations and why they were being performed, even though they had consented to undergo them. Thus the results clearly show that more information should be given to patients and that the method of giving it should be improved. It is unfair to assume that the patient is not interested in his condition or treatment simply because he does not ask questions: he may need help in talking about his fears and anxieties and in clarifying misconceptions.

\section{WHAT INFORMATION SHOULD BE GIVEN?}

The patient care team must decide how much information is going to be given to each patient. In certain standard procedures it is only right that he is told what is being done-for example, when an intravenous infusion is being sited he should be told why it is necessary, its duration, and what the fluid is. Similarly, when a patient is prepared for theatre he should understand exactly what the operation consists of and the reasons for the necessary preparations.

Sometimes discretion is obviously needed in the amount of information to be given. For instance, the consultant may not wish a patient with a terminal illness to know the full extent of his condition. This should be respected by the rest of the medical team. Moreover, in some cases the patient's capacity for understanding will limit what he can be told, but for non-Englishspeaking patients strenuous efforts should be made to use an interpreter. Account must also be taken of the patient's physical and emotional condition and of the suitability of the occasion when he is to be given information. One aspect of treatment that the patient is often not told about is the sensations likely to be experienced in a given procedure; in particular, pain should not be minimised but reassurance given that it can be relieved.

\section{HOW SHOULD INFORMATION BE GIVEN?}

Information is usually given verbally. This enables the patient to ask about anything he does not understand and to talk about his fears. He may not feel relaxed enough, however, to ask the doctor to explain something that may frighten him, and it is here that the nurse has an important part to play in both explaining to the patient relevant information and conveying, confidentially, the patient's fears to the doctor. As various members of the medical staff care for the patient, it may be useful for each to discuss with the patient his particular role. For instance, the anaesthetist or anaesthetic nurse could visit the patient before the operation to dispel natural anxieties.

The patient may also receive information by means of written material, certain standard procedures lending themselves to this form of communication. With this in view I drew up some specimen information sheets to show how such information might be presented (see appendix). Finally, I devised a procedure that would ensure that the patient received information relevant to his care. It necessitates using a simple check list, which would be kept in every patient's medical notes. It would be filled in as information was given and kept updated (figure). It would be the responsibility of the senior nurse on duty to ensure that any relevant information had been given before, for example, an operation. Any member of the patient care team could fill in the check list, but obviously some aspects of the information might be given only by the doctor. This scheme precludes the situation 


\begin{tabular}{|c|c|c|c|c|}
\hline $\begin{array}{l}\text { Name } \\
\text { Hospital No. EA } 7845 \\
\text { Date of birth } 4 / 4 / 56\end{array}$ & & $\begin{array}{l}\text { Diagnos } \\
\text { Natione } \\
\text { Mother }\end{array}$ & $\begin{array}{l}\text { is bancew } \\
\text { ity colect. } \\
\text { ongue Apan }\end{array}$ & $\begin{array}{l}\text { Consultant Af Brown } \\
\text { HPIHS S.Sill }\end{array}$ \\
\hline \multirow{2}{*}{ Topic } & \multicolumn{2}{|c|}{ Information } & \multirow{2}{*}{$\begin{array}{l}\text { Signature } \\
\text { and date }\end{array}$} & \multirow{2}{*}{ Comments } \\
\hline & Written & Verbal & & \\
\hline Observations & & $x^{\prime}$ & Sniti & Frequent after ceperation \\
\hline Specimens & & $x$ & Sth inay & \\
\hline Tests & $x$ & $x$ & $\begin{array}{l}\$ 777 \\
\text { Siil }\end{array}$ & sariim enema explained \\
\hline Blood samples & & $x$ & $\hat{e} \cdot \dot{u} i$ & \\
\hline Drugs & & $x$ & $8 / 777$ & Mecessity of necinusin explained. \\
\hline Diet & $x$ & $x$ & jinuith & how roughage sue operatively \\
\hline$x$-rays & $x$ & $x$ & s/giel & . \\
\hline Apparatus & $x$ & $x$ & $8 / 777$ & Glax wod explained \\
\hline \multicolumn{5}{|l|}{ ECG } \\
\hline IV infusion & $x$ & $x$ & sth thay & \\
\hline Preoperative routine & $x$ & $x$ & Sth thay & \\
\hline Anaesthetic & $x$ & $x$ & 27,177 & Cnausthetwit's nisit arraurged. \\
\hline Operation & $x$ & $x$ & $8 / 7177$ & 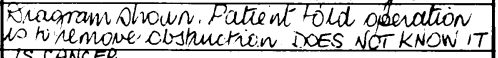 \\
\hline Drains & & $x$ & Lnict & 3asp und ippliancies demowshaked. \\
\hline \multicolumn{5}{|r|}{ 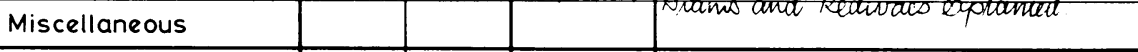 } \\
\hline $\begin{array}{l}\text { Continuing care } \\
\text { Societies }\end{array}$ & $x$ & $x$ & 5/7/7ita & $\begin{array}{l}\text { bovactomy waiety hiéval the quent. } \\
\text { bisit fran past patrent ananged. }\end{array}$ \\
\hline Appliances & $x$ & $x$ & 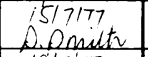 & Creocriptrin exenotion \\
\hline Drugs & & $x$ & s.tiul & belevac chalted to take home. \\
\hline Appointment & $x$ & $\times$ & dig/7.77 & fon 6/5x \\
\hline
\end{tabular}

Amplification:

where one team member does not inform the patient of something, thinking that someone else will. It also ensures that a tight check is kept on exactly what the patient has been told and provides an easily accessible record for any of the medical team to refer to before speaking to the patient. Finally, an important part of the information-giving procedure would also be to ensure that adequate stocks of booklets and information sheets relevant to the ward were kept within easy access. A note that a patient had had such information booklets would also be made on the clieck list.

\section{Appendix}

I envisage that the following information would be presented in an easy-to-read, humorously illustrated booklet.

\section{THE DRIP}

Sometimes a drip is necessary as part of your treatment. You may have heard it referred to as an intravenous infusion or an IVI. IVIs are used for many reasons, such as administering drugs (for example, antibiotics), putting special fluids through (for example, blood), or providing the necessary fluids, food, and minerals that you require when you cannot eat.

The doctor will put up the drip, which takes only a few minutes. It is a similar procedure to that of taking a blood sample: the doctor inserts a needle into one of the veins in your arm, and it is through this that the fluid in the bottle will pass. The needle is then strapped into position and the arm splinted to limit movement. This is to prevent the needle moving out of the vein.

The length of time for which the drip remains in place varies with each patient. It may be necessary to move the needle into another vein if it becomes dislodged. This is because the fluid, instead of running into the vein, runs into the surrounding tissues, and the arm becomes red and swollen. The drip is then said to have "tissued." The swelling will gradually go down after a few days as the fluid is absorbed, and this is nothing to worry about.

The fluid in the plastic pack or bottle varies with each patient and may be glucose and water (dextrose) or salt and water (saline), or a mixture, and it may contain minerals as well. Instead of the fluid going into the blood stream via the stomach as it would normally when you drink, it bypasses the stomach completely. It will, however, still leave the body in the normal way as urine, so don't be surprised if you pass water frequently.

Blood-When blood is being transfused (perhaps to replace blood loss after an operation or when the body's iron supply is low) the procedure entails regular checks of your temperature, pulse, and blood pressure. This is because the blood has come from somebody else (the donor) and the two bloods must be checked for compatibilitythat is, that they mix satisfactorily. This is done by specially trained staff in the pathology laboratory, but it is also necessary to observe the recipient (that is, you). These checks may seem frequent but are just routine.

\section{PREOPERATIVE AND POSTOPERATIVE CARE}

\section{Before the operation}

Before an area where hair grows is operated on it is shaved. This is just to allow the skin to be thoroughly cleansed and ensure that no infection will be taken into the incision.

Suppositories may be administered before some operations to empty the contents of the lower bowel. It is then easier for the surgeon to see what he is doing and for you to open your bowels afterwards. One or two suppositories are given into the back passage, and while no one will pretend that it is a pleasant experience, it should not be painful.

You may see a nurse put a notice above your bed saying "nil by mouth," or simply "NBM." This means that from the time the notice is put up until you go to theatre you will not be allowed to eat or drink anything. When you are under the anaesthetic you may vomit, and fluid might get into the air passage by mistake when you are unconscious, with dangerous results. If the stomach is empty this 
cannot happen. A doctor or nurse will tell you when you can eat and drink, but this will not be until after the operation.

Usually about an hour before the operation you will be given an injection known as the premedication, or "premed." It will help to relax and make you feel sleepy before you are anaesthetised, so that the anaesthetic is easier and safer to administer. This injection is usually given into the buttock or leg, and once it is given you must stay in bed because it will make you drowsy. It may also make your mouth dry, but on no account must any drink be taken. Many people do not remember being taken to the operating theatre because the premed has made them so sleepy. Should you be awake, however, you may be surprised to find everyone dressed in gowns, boots, and hats. This helps prevent bacteria being brought into theatre. The anaesthetic is nearly always administered into a vein in the back of the arm or hand, and within about 10 seconds you are asleep. The doctor who puts you to sleep stays to look after you during the operation, so there is no danger of you waking up in the middle.
After the operation

After the operation you will be taken to a room called "recovery," where a nurse stays with you until you wake up. Once you are awake a nurse from your ward will come and collect you and take you back to your bed. Pain relievers will be administered if you want them, and you will be allowed to sleep. A nurse will come regularly to see how you are feeling and record your pulse and blood pressure, so don't worry if she seems to be coming a lot: it's routine after an operation.

The day after your operation it is usual to try and get you moving, but this depends on the type of operation you have had. You may be up and walking the next day, since early mobilisation reduces the risk of certain complications.

This paper was written when I was a student nurse.

(Accepted 14 fune 1979)

\title{
Medical Controversies
}

\section{Which appliance or aid?}

\author{
W V JAMES, P V SCOTT, A J COLLIER
}

British Medical fournal, 1979, 2, 314-316

Mr W V James was asked by the $B M \mathcal{F}$ to present a case for a service providing comparative evaluation of expensive appliances and aids. His article, published below, was then sent to an anaesthetist and a deputy secretary of the Department of Health and Social Security, and all three met to discuss the topic with one of the $B M F$ medical editors, Dr Tony Smith, acting as chairman.

\section{Working paper}

The housewife has the benefit of a family at hand to perform comparative evaluation of items such as soups, toilet rolls, or soap, and she probably takes little heed of the advertising on the labels. When it comes to more expensive and infrequently bought items, she finds that home comparative evaluation is more difficult. Happily there is a consumer organisation to look after her interests, and it arranges trials of these more expensive items. The results of these comparative trials are available to her in Which? Through this magazine a consumer can see what is available for the needs, and the relative merits, demerits, and costs, and finally a "best bu," are suggested.

The consumer and prescriber of expensive appliances and aids does not have the benefit of a service providing comparative

\footnotetext{
Withers Orthopaedic Centre, Musgrave Park Hospital, Belfast BT8 TJB

W V JAMES, FRCS, consultant orthopaedic surgeon

Bromsgrove General Hospital, Bromsgrove

P V SCOTT, MB, FFARCs, consultant anaesthetist

Department of Health and Social Security, London SE1 6BY

A J COLLIER, CB, deputy secretary
}

evaluation in the United Kingdom, and he only rarely sees the results of independent trials of individual items. He has, therefore, to rely on the advertisements of those making the items, which often seem to omit details of defects, costs, and whether they are inferior to other products in the same category. In all fairness, it is difficult for a manufacturer of appliances and aids to get an independent comparative evaluation and to get the results published in a reputable journal.

Evaluation is not a simple matter, and comparative evaluation is even more difficult. In order to provide adequate results, there has to be an adequate series. In order to accumulate enough information in a reasonable time, it may be necessary to employ the services of several centres at the same time. The time factor is crucial, for otherwise a trial can drag on to the point where information gained is out of date. There are, in fact, relatively few centres in the United Kingdom that have the right clinical facilities, the right staff to perform an evaluation, and the right equipment. Some centres might be more suitable for certain trials than others. An essential factor in such multicentre trials is an independent team that selects suitable centres, evolves the protocol for the trial, and arranges and monitors the trial. Finally, the team produces an analysis of the results, and also a summary for distribution.

Even when the evaluation is completed, there are problems in getting the results to those concerned. The wide variety of specialties involved in prescribing appliances and aids means that the results should be published in a wide variety of journals, hardly any of whom would regard such articles as being of prime interest to them. The only journal common to all would be the British Medical fournal, but it is not designed to be the sole outlet for specialised information on appliances and aids. Prosthetics and Orthotics International is an excellent journal devoted to the problems of appliances and aids, but is relatively young and not yet widely read in the United Kingdom. The excellent series of booklets on Equipment for the Disabled provides much information on aids, but is not involved in evaluation or comparative evaluation. 